\title{
A EVOLUÇÃO HISTÓRICA DAS OUVIDORIAS: DA PARTICIPAÇÃO REIVINDICATÓRIA POR MELHORIAS NAS POLÍTICAS PÚBLICAS AO EMPOWERMENT DOS CIDADÃOS
}

\author{
Dionisio Moreno Ferres ${ }^{1}$
}

\begin{abstract}
Resumo
O presente artigo reflete sobre a vocação das Ouvidorias para ser um espaço neutro, que permite a participação dos cidadãos no controle da qualidade na Administração Pública, no sistema democrático da atualidade. Observa-se uma crise de confiança na Administração Pública, alavancada por inúmeros problemas político-administrativos, e uma urgência pela sua adaptabilidade na composição de uma rede participativa e de controle da qualidade das atividades administrativas que acompanhe e responda à moderna concepção da sociedade em rede. A transparência e a eficiência na Administração Pública são princípios que fazem parte da missão das Ouvidorias na estrutura do Estado. Com isso elas se tornam representantes legítimas dos cidadãos para reivindicar o aperfeiçoamento das instituições, a propositura de correções, adequação de políticas públicas e o desenvolvimento de ações em atenção aos cidadãos. As Ouvidorias, como espaços de interação e conexão dos cidadãos com a Administração Pública, constituem a melhor opção para a restituição da confiança dos representados em seus representantes, dando-lhes legitimidade política para executar as mudanças. Representam espaços inteligentes para uma gestão pública moderna e eficiente. A ausência desse espaço na moderna Administração Pública significa a demora na identificação de problemas e consequentemente dificuldades de reação às crises, a perda de capacidade e legitimidade administrativa, o distanciamento das realidades sociais, a perda da confiança e a piora da qualidade de vida dos cidadãos.
\end{abstract}

Palavras-chave: Ouvidorias. Participação Democrática. Sociedade em Rede. Gestão Pública. Eficiência Administrativa. Transparência. Informação. Controle e Qualidade de Vida.

1 Advogado na área do consumo com atuação por mais de 25 anos no Sistema Financeiro Nacional e em Ouvidorias. Especialista em direitos do consumidor e direito ambiental. Mestre em Comunicação e Semiótica pela PUC/SP. Doutorando em Comunicação e Semiótica pela PUC/SP pela mesma faculdade. (dionisio.254@adv.oabsp.org.br) 


\begin{abstract}
This article reflects on the Ombudsmen vocation to be a neutral space, which allows citizens participation in the quality control in Public Administration in today's democratic system. There has been a crisis of confidence in Public Administration, leveraged by innumerable political and administrative problems, and an urgency for its adaptability in composing a participatory control network in the quality of administrative activities that accompany and respond to the modern conception of the networked society. Transparency and efficiency in Public Administration are the principles that compose the Ombudsmen's mission in the structure of the State. Ombudsmen, as spaces for interaction and connection between citizens and the Public Administration, are the best option for restoring the confidence of the represented in their representatives, giving them the political legitimacy to carry out changes. They represent smart spaces for modern and efficient public management. The absence of this space in modern Public Administration means the delay in identifying problems and, consequently, difficulties in reacting to crisis, the loss of administrative capacity and legitimacy, the detachment from social realities, the loss of confidence and the worsening of the citizens' quality of life.
\end{abstract}

Keywords: Ombudsmen. Democratic Participation. Networked Society. Public Administration. Administrative Efficiency. Transparency. Information. Control and Quality of Life. 


\section{INTRODUÇÃO}

Como bem salientaram Stephen GOLDSMITH e William D. EGGERS² "no século XX, a burocracia governamental hierárquica foi o modelo organizacional predominante utilizado para a prestação de serviços públicos"( 2006, p. 21).

No Brasil não foi diferente. Nossa República, desde sua origem, mostrou ser incapaz de oferecer qualidade de vida de forma igualitária e justa aos seus cidadãos.

O sistema democrático brasileiro demonstra fragilidades sedimentadas há décadas, "não é exagero a constatação segundo a qual historicamente a democracia no Brasil foi intermitente e efêmera" (SEGATTO, 2015, p. 25).

Um sistema clientelista, patrimonialista e corporativista, que dificulta a emancipação de grande parte da população, impossibilitando uma experiência democrática em plenitude, foi o que permaneceu historicamente em nosso país. Essa característica presente ao longo de nossa história republicana causava o distanciamento entre representantes e representados, e estes, por sua vez, desprovidos de informação, mantinham-se numa situação passiva de receptividade.

Não houve uma experiência participativa efetiva na vida pública. As decisões sempre foram tomadas à margem da sociedade. Diferentemente do que muitos acreditam, com a ditadura militar, a situação política do Brasil em termos de participação do povo pouco mudou efetivamente, apenas institucionalizou-se a rejeição às manifestações.

Com a ditadura houve o sufocamento definitivo das manifestações populares e da sociedade civil organizada, reprimindo com o uso da força as manifestações de inconformidade com o sistema vigente. Nesse sistema não houve espaços que autorizassem a existência de uma Ouvidoria no âmbito da Administração Pública.

Como foi expresso pelo ilustre professor Goffredo TELLES JÚNIOR (1977), na Carta aos Brasileiros, "a ditadura é o regime que governa para nós, mas sem nós". Toda essa inoperância sistêmica que dominou as esferas políticas e determinou um governo "para o povo, mas sem o povo", teve como seu principal resultado a ineficiência sistêmica do Estado e dos serviços públicos.

Nesse contexto, não é possível a constituição de espaços para que a população possa manifestar-se participando da Administração Pública por meio de reclamações, críticas, denúncias ou sugestões.

No Brasil, essas manifestações, ao inverso do entendimento que levou ao desenvolvimento do Ombudsman escandinavo, não eram vistas de forma benéfica, mas sim como um malefício para o Governo, que entendia a participação popular ou do cidadão apenas como questionamento e manifestação subversiva à ordem política.

Com a redemocratização e com a promulgação da Constituição Federal de 1988, considerada uma resposta às aspirações históricas por direitos sociais sustentadas por décadas pela população,

2 Stephen Goldsmith foi prefeito da cidade de Indianápolis (EUA) entre 1992 e 1999. É professor de governança e políticas públicas da John F. Kennedy School of Government e chefe de departamento no Ash Institute for Democratic Governance and Innovation, ambos da Universidade de Harvard. William D. Eggers é diretor global da Deloitte Research/Public Sector, membro sênior do Manhattan Institute Center on Civic Innovation. 
inaugura-se um novo capítulo na história republicana brasileira. Como nos conta José Antonio SEGATTO (2015, p. 58):

[...] no longo e complexo processo de transição do regime ditatorial para o Estado de Direito Democrático houve de fato, e sem dúvida alguma, uma ampliação dos direitos de cidadania - tanto civis, como sociais e políticos, quanto de "novos direitos" (da mulher, do jovem e do idoso, da população negra, dos portadores de necessidades especiais, dos homossexuais, do consumidor etc. ) -, o fortalecimento das instituições da sociedade civil e política, a ampliação das liberdades e a diminuição da iniquidade.

Toda essa inovação legislativa, surgida em razão da complexidade social e política na reabertura democrática, ampliou as garantias e os direitos, que agora passam a estar contidos na nova Constituição Federal, criando uma nova realidade democrática e política para o Brasil. Contudo, chegava a democracia política sem o desenvolvimento de uma cultura cívica enraizada, com maturidade e participação dos cidadãos na Administração Pública de forma "efetiva", ou, como preferem alguns, de forma "ativa", permanecendo infelizmente aquela passividade histórica.

A falta de atenção aos principais anseios da população, às suas principais carências e vulnerabilidades esvaziara a execução de políticas públicas; governo após governo permanecia-se sem grandes mudanças. Somente após a reabertura democrática, com a promulgação da Constituição Federal de 1988, em que se firma a vontade em corrigir ou ao menos atenuar essa falta de diálogo e de atenção reduzindo as distâncias, a inovação ganhou impulso em alguns segmentos da sociedade, como foi o caso dos movimentos sanitaristas, dos direitos dos consumidores e do jornalismo, dos quais julgamos oportuno especificar algumas qualidades marcantes na construção dos diálogos participativos em torno da Administração Pública e dos quais entendemos derivar importantes ações que colaboraram com a formação do instituto das Ouvidorias no Brasil.

\section{OS PROTAGONISTAS DA CULTURA PARTICIPATIVA NA REDEMOCRATIZAÇÃO DO BRASIL: O JORNALISMO E OS MOVIMENTOS SANITARISTAS E CONSUMERISTAS}

É nesse período que a imprensa jornalística, como portadora da informação, que é o instrumento de emancipação social das liberdades, resolve criar oficialmente e com certa publicidade a primeira experiência de Ombudsman do jornalismo brasileiro e na América Latina. Trata-se do Ombudsman do jornal Folha de S. Paulo, tendo à frente o jornalista Caio Túlio Costa, na tentativa de trazer para nossa imprensa jornalística experiências bem sucedidas do Washington Post e El País.

Como relata Paula Cesarino COSTA (2017, p. 39), em 24 de setembro de 1989, a primeira página anunciava: "Ombudsman traz ao leitor os erros da Folha", anunciando ao grande público a coluna de estreia de Caio Túlio Costa, como primeiro Ombudsman do jornalismo brasileiro e latino-americano. O destaque dizia: "quando alguém é pago para defender o leitor".

Estamos falando de um momento em que não existiam os avanços das Tecnologias da Informação e Comunicação (TICs), em que a imprensa jornalística era exclusivamente impressa e 
tinha uma grande relevância, atrás da TV e do rádio. Foi uma ousadia, e ao mesmo tempo uma demonstração de compromisso e credibilidade para com seus leitores e toda a sociedade.

Tratava-se de uma exposição que muitos julgavam desnecessária, opinião ventilada não apenas no Brasil, mas também em países onde a democracia possuía maior grau de maturidade como nos EUA, em que a função de Ombudsman só foi criada pelo The York Times, o jornal de maior circulação, em 2003.

Com isso, podemos concluir que os espaços de manifestação do povo são espaços que representam incômodo, inconveniente e também receio. Sua criação exige níveis de maturidade democrática e de preparo cívico muito além dos discursos políticos. A constituição de espaços públicos, como é o caso das Ouvidorias, exige acima de tudo responsabilidade.

Nesse processo de amadurecimento democrático, os cidadãos brasileiros ganharam instrumentos legais de relevância para o cumprimento dos novos dispositivos constitucionais. Aparecem como grandes marcos legais de valorização da cidadania participativa e reivindicatória a Lei $n^{\circ}$ 8.080, de 19 de setembro de 1990, que dispõe sobre as condições para a promoção, proteção e recuperação da saúde, a organização e o funcionamento dos serviços correspondentes e dá outras providências, em grande parte fruto do ativismo do movimento sanitarista brasileiro, em especial do médico sanitarista Sérgio Arouca; e a Lei $n^{\circ}$ 8.078, de 11 de setembro de 1990, que dispõe sobre a proteção do consumidor e dá outras providências, resultado do ativismo de entidades de consumidores e das experiências de renomados juristas como José Geraldo Brito Filomeno, que, no Ministério Público do Estado de São Paulo, foi pioneiro na defesa dos direitos dos consumidores e já acumulava vasta experiência nessa área pouco conhecida e que carecia de leis capazes de responsabilizar aqueles que lesavam os cidadãos.

Embora esses diplomas legais não trouxessem expressamente a previsão de criação de Ouvidorias em seus dispositivos, eles anunciavam uma nova realidade para a democracia brasileira, que passa a exigir da Administração Pública maior atenção para as necessidades da população quanto à eficiência da máquina pública.

A criação dessas leis foi um momento histórico e significativo para a cidadania brasileira. No caso da saúde, passamos de uma cultura do benefício para a elaboração do entendimento de se tratar de um direito do povo e um dever do Estado (caput do art. 196 da Constituição de 1988), e esse dispositivo por si só já implicou uma reviravolta no sistema.

Com a elevação da saúde a direito social pela Constituição Federal, era também necessário definir os contornos desse direito e os das obrigações do Estado para assegurá-lo, e, nesse esteio, a Lei $n^{\circ} 8.080 / 90$ apresentou no caput do art. $2^{\circ}$ o que juridicamente entendemos como saúde. "A saúde é um direito fundamental do ser humano, devendo o Estado prover as condições indispensáveis ao seu pleno exercício". A lei teve o intuito de conceituar a saúde para assegurar que esse direito não fosse violado, mas, que havendo violação, os responsáveis fossem responsabilizados pelos danos causados.

A partir desse conceito jurídico, o parágrafo $1^{\circ}$ passa a detalhar o dever do Estado na saúde: "O dever do Estado de garantir a saúde consiste na formulação e execução de políticas econômicas e sociais que visem à redução de riscos de doenças e de outros agravos e no estabelecimento de condições que assegurem acesso universal e igualitário às ações e aos serviços para 
a sua promoção, proteção e recuperação" ( $\left(1^{\circ}\right.$ do art. $2^{\circ}$, da Lei $\left.n^{\circ} 8.080 / 90\right)$. (Destaque ausente no original.)

O destaque dado ao estabelecimento de condições que assegurem acesso universal e igualitário às ações e aos serviços para a sua promoção, proteção e recuperação, deve-se à importância dessas condições. Chamamos a atenção para esse ponto específico da lei porque entendemos que é nele que a Ouvidoria encontra sua legitimidade e essencialidade para assegurar a prestação de serviços conforme o disposto legalmente.

Se pensarmos na capilaridade operacional e na complexidade do Sistema Único de Saúde (SUS), conforme determinado no caput do art. $4^{\circ}$ da mesma lei, não teremos dúvida de que a qualidade na execução dos serviços e sua eficiência dependem da Ouvidoria como espaço de manifestação dos usuários para assegurar esse acesso.

Assim é também o Código de Defesa do Consumidor, Lei n 8.078/90 - do qual três qualidades especiais são destacadas por Cláudia Lima MARQUES (1994, p.142): "sua origem constitucional, sua definição como norma de ordem pública e sua característica como norma de interesse social”- , e no qual encontramos vários dispositivos que exigem uma atenção específica para a relação de consumo e para as manifestações dos consumidores quanto ao grau de satisfação para com o serviço prestado.

O Código de Defesa do Consumidor ( $C D C$ ), no atendimento às necessidades dos consumidores, entende como salutar não somente o acesso ao Judiciário como forma de justiça, mas reforça o entendimento de que devemos dar "incentivo à criação pelos fornecedores de meios eficientes de controle de qualidade e segurança de produtos e serviços, assim como de mecanismos alternativos de solução de conflitos de consumo" (inciso V do art. $4^{\circ}$, do CDC).

Ressaltamos que até então praticamente não existiam mecanismos alternativos de solução de conflitos, embora o Procon do estado de São Paulo tenha sido criado em 1976 e se dedicado às reuniões de negociação desde 1982. No início da década de 1990, a preocupação primordial no meio jurídico era em relação ao acesso à justiça, compreendendo a atuação do Judiciário como o mecanismo mais adequado para a solução das demandas, entendimento já superado na atualidade, quando o movimento pela desjudicialização e pelas formas alternativas de conflitos vem se consolidando no plano mundial.

Esse importante marco legal para o fortalecimento da cidadania brasileira não deixou passar despercebida a importância dos serviços públicos para a vida das pessoas. Podemos encontrar essa preocupação no art. $4^{\circ}$, incisos II e VII, e no art. $6^{\circ}$, inciso X do CDC.

Essa "codificação" consumerista foi constituída de forma jurídica, diferente da saúde, na qual a regulação se deu de forma administrativa, com a constituição do SUS e seus regulamentos, mas, o que é mais importante: ambos os dispositivos legais oferecem modelos e experiências complementares para fins de cidadania. Ambos caminham para a mesma direção finalística, ou seja, a participação do cidadão nas decisões, entendendo essa participação como um direito e não como uma vontade discricionária dos órgãos da Administração Pública, conforme a conveniência de quem esteja na gestão.

Ambos, cada qual com sua peculiaridade e especificidade, alertam para a necessidade da participação dos cidadãos, seja por conselhos ou por canais de acesso antes, durante e após a prestação dos serviços.

Essa construção social, mesmo que advinda de movimentos distintos, contribuíram de forma sig- 
nificativa para a evolução de uma consciência popular coletiva quanto à necessidade de eficiência na gestão pública. Nessa época não havia de forma expressa um dispositivo que pudesse obrigar a Administração Pública a essa vontade do povo. Essa vontade coletiva ganhou forma normativa como sabemos em 1998, com a Emenda Constitucional $n^{\circ} 19$, que inclui no texto constitucional a eficiência como um dos princípios da Administração Pública.

Embora não existam dispositivos expressos sobre Ouvidorias nos dispositivos comentados, em uma interpretação sistêmica e estrutural da sociedade, podemos encontrar indícios suficientes para concordar que mais cedo ou mais tarde as Ouvidorias viriam incorporar essa vocação, como resposta a todas as necessidades advindas da reivindicação que reclama pela melhoria da qualidade dos serviços prestados ao cidadão.

\section{A CULTURA DA PARTICIPAÇÃO DEMOCRÁTICA ATRAVÉS DO OMBUDSMAN OU OUVIDORIAS NO CONTEXTO LATINO-AMERICANO}

Como nos relata Paula Cesarino COSTA (2017, p. 39), a iniciativa da Folha de S. Paulo em criar em 1989 o primeiro Ombudsman do jornalismo brasileiro não foi uma ação pioneira apenas no âmbito do Brasil. Essa iniciativa foi uma novidade também na América Latina e no mundo lusófono. No contexto latino-americano, as Ouvidorias encontraram muita resistência para sua instituição.

A falta de infraestrutura adequada para a prestação de serviços públicos de qualidade e de forma equânime para todos os cidadãos é uma realidade em muitos países latino-americanos. As crises econômicas agravam as dificuldades de realização plena dos direitos sociais básicos, como saúde, educação, segurança, segurança alimentar e saneamento básico, que ainda permanecem distantes de muita gente.

A presença de antigas formas colonialistas que se perpetuaram ao longo de séculos na América Latina cria dificuldades estruturais para a realização democrática em sua plenitude. Os avanços na justiça social em países repletos de carências e vulnerabilidades se devem em grande parte aos movimentos reivindicatórios por políticas sociais igualitárias, que acabaram tomando corpo em razão da ausência de uma política de atenção e correção a essas carências, resultado da força transformadora de seu ativismo, como comentamos no capítulo anterior.

Como nos conta Margot Soria SARAIVA (1997, p.135):

[...] esta construção coletiva da história e da democracia, a qual tem, na reivindicação do reconhecimento à diversidade e ao respeito à liberdade individual, seu impulso, foi entendida na América Latina como a demanda para a realização de mudanças profundas no político, no social e no econômico, sendo que a base destas mudanças foi a transformação do caráter do Estado e modificação do seu papel.

Diante desse quadro de dificuldades, o Brasil apresenta certo protagonismo em termos de América Latina no avanço das perspectivas democráticas, e com isso espaços como as Ouvidorias ou Ombudsman encontraram os meios propícios para seu estabelecimento, desde a criação 
da primeira Ouvidoria Pública Municipal de Curitiba, em 1986, concomitantemente ao momento da reabertura democrática.

Com atrasos estruturais na sociedade, num Estado ineficiente, burocrático e insuficiente para atender com qualidade as demandas de seus cidadãos, o Ombudsman apresenta-se como um dos mais avançados espaços da administração para a melhoria contínua dos serviços públicos, o aperfeiçoamento das instituições e a construção de políticas públicas participativas, dentro das necessidades da população.

Nos últimos anos, o Ombudsman parece acompanhar os avanços democráticos preenchendo lacunas que antes distanciavam os representantes dos representados dentro da administração.

Muito precisa é a constatação de LAGUARDIA (2000, p.11) quando afirma que "o desenvolvimento das funções do Estado, tão acelerado nos últimos anos, tornou insuficientes os meios tradicionais de proteção dos direitos dos governados frente à Administração Pública", como também o aperfeiçoamento sistêmico no cumprimento de suas finalidades administrativas de gestão e de justiça social e que as Ouvidorias representam um espaço adequado para a proteção de direitos e aperfeiçoamento do Estado.

E enfatiza ainda que "a função específica do 'Ombudsman', 'defensor do povo', 'Ouvidor' ou 'procurador dos direitos humanos' é a de fiscalizar a Administração Pública ou, num sentido mais amplo, em alguns países, fiscalizar a atividade administrativa, a judicial e mesmo a militar" (LAGUARDIA, 2000, p.12). E conclui que "a figura do Ouvidor, do defensor do povo, tem uma legitimidade essencial no sistema democrático" (idem, p. 19).

Diante de tantos benefícios que uma Ouvidoria pode oferecer para as instituições e seus governos, uma das perguntas que podemos fazer é: por qual motivo ela não é utilizada amplamente? A resposta pode estar em uma única palavra "incômodo". As Ouvidorias como um canal de amplo acesso do povo e para o povo podem significar um espaço desconfortável para intenções não republicanas ou desrespeitosas para com a população.

Esse "incômodo" ocasionado pelas funções do Ouvidor é um desmotivador para a propagação de sua atividade como sendo essencial para a eficiência das instituições e para a consolidação efetiva dos direitos e garantias dos cidadãos, verdadeiros mandatários do poder. Nas palavras de LAGUARDIA (2000, p.19):

O controle da atividade governamental e dos órgãos do poder, em defesa dos direitos dos habitantes, é uma coroação necessária para a realização do Estado de Direito e o fortalecimento das novas instituições. Como o defensor do povo deve resolver sobre situações concretas, sobre fatos reais, muitas vezes conflituosos (na verdade, sempre conflituosos), suas competências são altamente participativas.

Todo esse histórico, tanto no Brasil como na América Latina, foi um processo evolutivo em termos legislativos e de participação democrática, não obstante, como dissemos anteriormente, nossa cultura participativa trazer em sua memória pouca experiência em ativismos e reivindicações sociais; foram porém esses movimentos referenciados anteriormente que iniciaram as mudanças constitucionais e estruturais, fazendo-se constar nos termos da lei esses direitos. Assim, denota-se que os avanços foram muito mais na esfera legal que em termos culturais e de consciência parti- 
cipativa por parte dos cidadãos, excetuando-se os movimentos já citados. Alguns estudiosos veem essa peculiaridade como normal para uma república como a brasileira, em que os cidadãos ainda não tiveram tempo para realizar a experiência do exercício da democracia plena e adquirir o hábito da participação efetiva, portanto, nada mais natural que essa autorização ou esse empowerment ocorresse por meio de normas protecionistas que buscam firmar direitos e garantias e que fortalecem essa participação.

\section{DETERMINAÇÕES LEGAIS PARA O ESTABELECIMENTO DE OUVIDORIAS PÚBLICAS EM TODOS OS ÓRGÃOS DA ADMINISTRAÇÃO PÚBLICA DIRETA E INDIRETA}

A escala de mudanças mantém ritmo acelerado e contínuo. Temos a percepção de que o tempo urge em meio a tantas novidades científicas e tecnológicas. A inovação aparece como uma palavra-chave, de ordem, nos cenários econômicos. Nesse sentido, não é mais possível uma Administração Pública alheia aos principais problemas de qualidade de vida da população. Para solucionar isso tornou-se imprescindível a criação de canais de acesso, para que os cidadãos estejam em sintonia com os novos tempos e os novos modelos tecnológicos de comunicação. Não há mais espaços para processos arcaicos e burocráticos que dificultem esse diálogo entre cidadãos e Administração Pública.

$\mathrm{Na}$ tentativa de manter os níveis de aproximação e de efetividade no tratamento das manifestações dos cidadãos, entra em vigor a Lei $n^{\circ} 13.460$, de 26 de junho de 2017, que dispõe sobre a proteção e defesa dos direitos do usuário dos serviços públicos da Administração Pública, com um cronograma de adequação, conferido pelo art. 25 e incisos.

Como podemos observar, a lei sancionada estabelece regras básicas para a participação, proteção e defesa dos direitos do usuário dos serviços públicos prestados (caput do art. $1^{\circ}$, da Lei $n^{\circ}$ 13.460/2017). Essa lei foi sancionada quase um ano após o Banco Central do Brasil, por meio do Conselho Monetário Nacional, editar a Resolução n 4.539, que veio a público no DOU de 28/11/2016.

Faremos aqui um importante paralelo entre essas duas importantes normas, mesmo que de hierarquias e competências bem diferentes, na tentativa de demonstrar o quanto nossa sociedade democrática tem avançado positivamente à revelia dos abusos e escândalos que têm afetado a Administração Pública e manchado sua reputação e a confiança perante a população.

Um dos pontos relevantes dessas novas normas é sem dúvida a atenção à questão da transparência. Como sabemos, em 2011, foi sancionada a Lei $n^{0} 12.527$, que definiu regras em nosso ordenamento jurídico sobre o acesso à informação na Administração Pública.

Merece destaque o disposto no caput do art. $3^{\circ}$, que define: "Os procedimentos previstos nesta Lei destinam-se a assegurar o direito fundamental de acesso à informação", o qual traz regras para o cumprimento do direito à informação constante no inciso XXXIII, do art. $5^{\circ}$ da Constituição Federal. Além disso, informa que esses acessos "devem ser executados em conformidade com os princípios básicos da Administração Pública”, ou seja, em conformidade com os princípios do art. 37 da Constituição Federal.

Todos esses dispositivos possibilitam a garantia do acesso a informações sobre a Administração 
Pública em favor da sociedade. Esse processo repercute positivamente para a transparência das instituições e possibilita ao final um maior controle da Administração Pública, o que também aparece no inciso $\mathrm{V}$, do art. $3^{\circ}$ da lei, que expressa como uma das suas diretrizes o "desenvolvimento do controle social da Administração Pública".

Não há dúvida de que a transparência passou a compor os valores da sociedade. Uma sociedade em que a Administração Pública possui mecanismos adequados de acesso à informação, gestão e controle dos serviços públicos por parte da população tem sua credibilidade majorada, sua reputação fortalecida no mercado e com seus cidadãos, atraindo investimentos pela segurança e confiança.

Esse movimento de mudança não está presente apenas na Administração Pública, é visível no setor privado, impulsionado pelo poder de decisão dos consumidores, cada vez mais conectados com as novas redes digitais, e a transparência nas ações tem sido um componente cada vez mais reivindicado.

O poder passa para as mãos do consumidor que, com um clique, poderá deixar de ser cliente ou usuário de determinado serviço passando para outro concorrente.

Como informa Klaus SCHWAB (2016, p. 59):

[...] esta tendência de digitalização está atualmente caminhando para a maior transparência, significando mais dados da cadeia de fornecimento, mais dados na ponta dos dedos dos consumidores e, portanto, mais comparações ponto a ponto (peer-to-peer) sobre o desempenho dos produtos que transferem poder aos consumidores.

Se por um lado o mercado aumenta seu poder de captura de dados para utilizá-los a seu favor, os consumidores por sua vez também passam a fazer uso de informações manifestadas por outros consumidores nas redes sociais, plataformas e aplicativos, que conferem um empowerment diante dos fornecedores de produtos e serviços.

$\mathrm{Na}$ Resolução $n^{\circ} 4.539$, do Banco Central, estão inseridos nos princípios da política institucional de relacionamento com clientes e usuários a transparência (art. $2^{\circ}$ ) e, logo na sequência, no parágrafo único do art. $3^{\circ}$, temos no inciso I - a prestação de informações a clientes e usuários de forma clara e precisa, a respeito de produtos e serviços; e no inciso II - o atendimento a demandas de clientes e usuários de forma tempestiva.

Toda essa movimentação regulatória demonstra total sintonia com os demais diplomas legais comentados, possibilitando uma mudança no relacionamento com os consumidores e na forma de relacionar-se com eles, sendo que isso se reflete também no âmbito da Administração Pública e de seus serviços oferecidos aos cidadãos.

Nas análises sempre muito precisas de Néstor García CANCLINI (2006, p. 29.), "mudanças na maneira do consumidor alteraram as possibilidades e as formas de exercer a cidadania", que passa a viver uma ambivalência cotidiana na sociedade, "junto com a degradação da política e a descrença em suas instituições, outros modos de participação se fortalecem".

A velha estrutura de governo constituída por séculos de história passa por uma transformação nas bases. Como salienta Donald KETTL, professor da Universidade da Pensilvânia, no prefácio do livro de GOLDSMITH e EGGERS, "tornou-se emergente uma nova forma de gestão pública para 
conciliar a tradicional hierarquia top-down (de-cima-para-baixo), construída em linhas verticais de autoridade, com as redes emergentes construídas em linhas horizontais de ação".

Outro ponto de relevância nessa evolução está na forma de acesso à informação. Muitas possibilidades foram desenvolvidas e continuam a aparecer como canais de acesso. A multicanalidade proporcionada pelas TICs abrem infinitas possibilidades de comunicação na sociedade.

Como aponta Rogério da COSTA (2005, p. 236):

[...] temas como "inteligência emergente" (Steven JOHNSON, 2001), "coletivos inteligentes" (Howard RHEINGOLD, 2002), "cérebro global" (HEYLIGHEN et al., 1999), "sociedade da mente" (Marvin MINSK, 1997), "inteligência conectiva" (Derrick de KERCKHOVE, 1997), "redes inteligentes" (Albert BARABASI, 2002), "inteligência coletiva" (Pierre LÉVY, 2002) são cada vez mais recorrentes entre teóricos reconhecidos.

Todas essas novas realidades passam a fazer parte da vida das pessoas. É preciso urgência por parte da Administração Pública na aplicação dessas novas tecnologias a serviço da qualidade dos serviços e eficiência na administração.

Nesse sentido nos impressiona como uma criação do início do século XIXna Escandinávia se mostra tão atual e tão necessária, em meio a tantas transformações sociais, nas modernas democracias.

Evidencia-se uma impressionante atualidade do Ombudsman ou Ouvidor nas democracias atuais. Nesse modelo percebemos com muita clareza a adaptação da chamada identidade socioespacial para a identidade sociocomunicacional. Essa mudança está no âmago das sociedades democráticas atuais. A constituição do chamado Ombudsman no início do século XIX estava muito arraigada em competências espaciais das burocracias. Hoje, as Ouvidorias modelaram uma nova perspectiva de atuação que deixa de ser espacial para ser comunicacional e fluida.

Tomando por base a definição de sociedade moderna feita por Anthony GIDDENS (2000), podemos entendê-la como "um complexo de práticas recorrentes que criam instituições", ou seja, nossas instituições são criadas a partir de práticas cotidianas recorrentes e contínuas. E segue o prestigiado autor: "tais práticas dependem dos hábitos e modos de vida adotados pelos indivíduos".

Nessa perspectiva, podemos compreender que nas modernas democracias a sociedade deve modelar as instituições como resultado de sua participação. As Ouvidorias são espaços de comunicação e informação entre a população e a Administração Pública que têm legitimidade para propor mudanças, modelando-a de acordo com a vontade de seus cidadãos.

A necessidade de espaços de diálogos entre a Administração Pública e os cidadãos usuários dos serviços está presente no $\S 3^{\circ}$ do art. 37 da Constituição Federal, cuja redação foi dada pela Emenda Constitucional n 19, de 1998: "A lei disciplinará as formas de participação do usuário na Administração Pública direta e indireta, regulando especialmente", continuando, mais especificamente ainda no inciso I do mesmo parágrafo: "as reclamações relativas à prestação dos serviços públicos em geral, asseguradas a manutenção de serviços de atendimento ao usuário e a avaliação periódica, externa e interna, da qualidade dos serviços".

Esse espaço de diálogo entendemos ser por vocação as Ouvidorias. Sua relevância institucional como facilitadora da participação, reclamação, reivindicação e avaliação dos serviços públicos possibilita o aperfeiçoamento dos órgãos públicos na visão dos cidadãos usuários dos serviços. 
Embora essa interpretação contenha indicativos de relevância para deduzirmos que as Ouvidorias seriam a melhor alternativa em atendimento aos dispositivos constitucionais retrocitados, carecíamos de uma lei mais específica sobre o assunto que trouxesse expressamente regras mais definidas para esse instituto.

Com a lei n 13.460/2017, as exigências para a presença de Ouvidorias Públicas na administração direta e indireta finalmente ganharam força normativa.

A lei que dispõe sobre a participação, proteção e defesa dos direitos dos usuários dos serviços públicos da Administração Pública dedicou um capítulo exclusivo para as Ouvidorias, além de um capítulo com regras procedimentais e operacionais sobre as manifestações.

Além disso, outros dispositivos interessantes merecem um breve destaque, como por exemplo a chamada Carta de Serviços (art. $7^{\circ}$ ), que visa garantir um mínimo de informação essencial para o acesso aos serviços e a avaliação continuada dos serviços públicos ( $\S 2^{\circ}$ do art. 23), estabelecendo que o resultado da avaliação deverá ser publicado integralmente no site do órgão ou entidade.

O objetivo desses dispositivos é cumprir o direito à informação. Com as novas Tecnologias da Comunicação e Informação (TICs), o antigo modelo administrativo, que "preservou a cultura política e práticas pretéritas" (SEGATTO, 2015, p. 59), passou a acumular constantes fracassos no atendimento das demandas dos cidadãos e parece não ter mais espaço na atualidade por força da lei.

Em síntese podemos dizer que a informação, o acesso, a transparência, a avaliação e o controle dos serviços estão nas mãos do cidadão pelo empowerment proporcionado pelos novos dispositivos legais. Além disso, os meios de comunicação, imersos nas novas realidades com a proliferação das redes sociais e tecnologias móveis de comunicação e informação, passaram a modificar os cenários políticos, as escolhas de candidatos, a interferir nas escolhas dos consumidores, e essas manifestações passaram a preocupar os governantes, que precisam entender e conhecer as opiniões dos eleitores. Caso contrário, as suas ações e de sua gestão estão fortemente fadadas ao fracasso. Não há mais espaço para distanciamento entre os cidadãos e a Administração Pública. A voz do cidadão tornou-se essencial não só para a Administração Pública, mas para os partidos políticos e para os candidatos.

Podemos considerar que as Ouvidorias conservam em suas funções cinco princípios fundamentais: ética; transparência (disclosure); equidade (fairness); prestação de contas (accountability); cumprimento das leis (compliance) (VALÉS, 2006, s/p.).

Todos esses princípios creditam à figura do Ouvidor uma legitimidade em suas recomendações como portador da opinião pública.

Como falamos anteriormente, as estruturas administrativas, constituídas para atender o cidadão e o seu bem-estar, muitas vezes acabam por se afastar dessa finalidade precípua pela própria complexidade do Estado, e as Ouvidorias representam uma reação a esses equívocos:

Pode-se dizer, de modo geral, que a sua disseminação é resposta a um fenômeno comum: a potencialidade de todas as burocracias de se manifestarem de modo insensível aos indivíduos. Demora, procrastinação, indiferença, tratamento rude, negligência, arbitrariedade, comportamento opressivo, arrogante e ilegítimo podem ser problemas estruturais de todas as hierarquias nas quais os empregados recebem ordens, poderes e recompensas derivados de escalões superiores. (VALDÉS, 2006, s/p.) 


\section{CONSIDERAÇÕES FINAIS}

Cabe-nos abrir um pequeno parêntese nas conclusões finais para trazer os conceitos democráticos da antiga Grécia, o qual o fazemos, pela obra de Platão, nas palavras "os governantes devem governar com sabedoria”. Esse preceito platônico, referência para qualquer cargo público, ainda repousa sobre a finalidade da res publica de produzir "o máximo de benefícios para o maior número de pessoas".

Da antiga democracia grega, passando pela escandinava do século XIX, chegando finalmente às democracias modernas, fica evidente a importância do Ombudsman ou Ouvidor para o aperfeiçoamento do sistema político, produzindo o máximo de satisfação para o maior número de cidadãos.

Assim sendo, impressionam-nos as possibilidades de governabilidade que as Ouvidorias proporcionam, essencialmente em razão da volumetria das informações que são captadas pelas manifestações dos cidadãos e disponíveis para uso da Administração Pública.

Vale a pena recordarmos as palavras do professor de ciências políticas da Universidade de Munique, WEINDENFELD (1997, p. 1), "nenhum ordenamento político está definitivamente estabelecido. Todo sistema político é constantemente questionado". Essas constatações fáticas feitas por Weidenfeld nos alertam para a mutabilidade da vida pública e suas instituições, e nos explicita ainda o dinamismo como uma condição da sociedade atual, cada vez mais suscetível às mudanças acontecendo progressivamente mais aceleradas.

Inevitavelmente, as instituições precisam acompanhar o dinamismo da sociedade, mantendo-se adequadas às novas realidades impostas pelas mudanças estruturais da civilização.

No cerne das mudanças estruturais da sociedade está o direito à informação que reclama cada vez mais por transparência na administração. Em nossos dias já não basta somente a informação para o empowerment do cidadão, embora sua essencialidade seja inquestionável, o dinamismo das inovações tecnológicas, a aceleração das relações humanas, a comunicação e a fluidez dos dados digitalizados, implicam novas exigências por parte da população, e a transparência é uma delas. Não é por acaso que a Lei no 13.460/2017 tem vários dispositivos ancorados na transparência que transmite aos cidadãos, uma mensagem de observância aos princípios democráticos e probidade nos atos administrativos.

Nesse contexto o conceito de Ouvidor ganha contornos definidos e específicos muito bem sintetizado por VALDÉS (2006) quando afirma que "fundamental ao conceito do Ouvidor, no Brasil, é sua habilidade de inverter a atenção da burocracia na direção do indivíduo, ao qual tem o dever de servir". O Ouvidor na Administração Pública está posicionado numa área de tensão, num espaço de questionamentos permanentes, e entende a transparência como um valor essencial para a continuidade do diálogo, ético, franco e aberto entre a Administração Pública e os cidadãos.

A participação democrática, a gestão pública e as políticas públicas se realizam plenamente nesse instituto. A perda de canais de comunicação permanentes como as Ouvidorias significa na prática a perda na capacidade informacional, um distanciamento das realidades sociais e, consequentemente, a demora na identificação de problemas e de reação a crises pela administração; por outro lado, sua criação e disseminação representam para os cidadãos empowerment, ou seja, empoderamento diante das decisões e consequentemente accountability administrativo. 
Empowerment e accountability têm o firme propósito de modificar estruturas arcaicas e corrompidas, transformando-as em espaços democráticos com eficiência dos serviços para a melhoria da qualidade de vida. Com a instituição das Ouvidorias em todas as esferas da administração, direta e indireta, conferimos mais efetividade ao empowerment dos cidadãos, rumo certo para o cumprimento do $\S 1^{\circ}$ do art. $1^{\circ}$ da Constituição Federal, que afirma categoricamente que "todo poder emana do povo", sendo este o princípio e o fundamento de nossa república democrática.

\section{REFERÊNCIAS}

BAPTISTA, Dulce (Org). Sociedade e Subjetividade: novos rumos e múltiplos sujeitos. São Paulo: Imaginário, 1997.

BRASIL. Constituição Federal de 1988. Disponível em: http://www.planalto.gov.br/ccivil_03/constituicao/constituicaocompilado.htm. Acesso em: 22 jun. 2018.

. Lei $n^{\circ}$ 12.527, de 18 de novembro de 2011. Disponível em: http://www.planalto.gov.br/ccivil_03/_ato20112014/2011/lei/l12527.htm. Acesso em: 22 jun. 2018.

Lei no 13.460, de 26 de junho de 2017. Disponível em: http://www.planalto.gov.br/ccivil_03/_ato20152018/2017/lei/L13460.htm. Acesso em: 22 jun. 2018.

Lei $n^{\circ} 8.080$, de 19 de setembro de 1990. Disponível em: http://www.planalto.gov.br/ccivil_03/leis/L8080. htm. Acesso em: 22 jun. 2018.

. Lei $n^{\circ}$ 8.078, de 11 de setembro de 1990. Disponível em: http://www.planalto.gov.br/ccivil_03/Leis//8078.htm. $\overline{\text { Acesso }}$ em: 22 jun. 2018.

CANCLINI, Néstor García. Consumidores e Cidadãos: conflitos multiculturais da globalização. Tradução de Mauricio Santana Dias. 6. ed. Rio de Janeiro: UFRJ, 2006.

COSTA, Paula Cesarino. De que vale a função de Ombudsman? Revista de Jornalismo ESPM, Edição Brasileira da Columbia Journalism Review, jul./dez. 2017, n. 20, ano 6.

DA COSTA, Rogério. Por um novo conceito de comunidade: redes sociais, comunidades pessoais, inteligência coletiva. Revista Interface - Comunicação, Saúde, v. 9, n. 17, p. 235-48, mar./ago. 2005.

GIDDENS, Anthony; PIERSON, Christopher. Conversas com Anthony Giddens: o sentido da modernidade.Tradução de Luiz Alberto Monjardim. 1. ed. Rio de Janeiro: Editora FGV, 2000.

GOLDSMITH, Stephen. EGGERS, William D. Governar em Rede: O novo formato do setor público. São Paulo/Brasília: Fundação Editora da UNESP/ENAP, 2006.

LAGUARDIA, Jorge Mario García. Os Defensores do Povo e os Direitos Humanos. Cadernos Adenauer: Acesso à justiça e cidadania, n. 3. São Paulo: Fundação Konrad Adenauer, 2000.

MARQUES, Cláudia Lima. O Código de Defesa do Consumidor e o Mercosul. Revista de Direito da Universidade Federal do Rio Grande do Sul, v. 10, Porto Alegre: Livraria do Advogado, jul.,1994.

SARAIVA, Margot Soria. Globalização e cidadania: Os desafios para a democracia na Bolívia. In: BAPTISTA, Dulce (Org). Sociedade e subjetividade: novos rumos e múltiplos sujeitos. São Paulo: Imaginário, 1997.

SCHWAB, Klaus. A Quarta Revolução Industrial. Tradução de Daniel Moreira Miranda. 1. ed., 5. reimpressão. São Paulo: Edipro, 2016.

SEGATTO, José Antonio. Política, relações sociais e cidadania. Brasília/Rio de Janeiro: Fundação Astrojildo Pereira/ Contraponto, 2015.

VALDÉS, Daisy de Asper y. Ética e Governança: Ouvidoria para a cidadania. Palestra apresentada no III Ciclo Étical em Brasília, em 19 de maio de 2006, sobre "ética e bem comum", no Centro Cultural Brasília - CCB - Brasília, DF.

WEIDENFELD, Werner. O futuro da democracia: projetos para o século XXI. Série Traduções. Tradução de Sperber S.C. Ltda. Fundação Konrad-Adenauer-Stiftung. Representação no Brasil, 1. ed., n. 11, 1997. 